\title{
A Cluster Randomized Trial of Adding Peer Specialists To Intensive Case Management Teams in the Veterans Health Administration
}

\author{
Matthew Chinman, PhD, \\ Research Scientist, VISN-4, Mental Illness Research, Education and Clinical Center, VA \\ Pittsburgh Healthcare; Senior Behavioral Scientist, RAND Corporation, Pittsburgh, Pittsburgh VA \\ Healthcare System, 7180 Highland Drive (151-R), Pittsburgh, PA 15206, 412 954-4338 \\ Rebecca S. Oberman, MA, \\ Health Science Specialist, VA Desert Pacific Mental IIIness Research, Education and Clinical \\ Center, Los Angeles, West Los Angeles VA Healthcare System, MIRECC, 11301 Wilshire Blvd., \\ 210A, Los Angeles, CA, USA 90073, 310 478-3711 x 48165 \\ Barbara H. Hanusa, PhD, \\ Senior Biostatistician, Center for Health Equity Research and Promotion (CHERP) \& MIRECC, \\ VA Pittsburgh Healthcare, Pittsburgh VA, 7180 Highland Drive, Pittsburgh, PA 15206, \\ 412-954-5220
}
Amy N. Cohen, PhD,
Co-Director, Health Services Unit, VA Desert Pacific Mental Illness Research, Education and Clinical Center, Los Angeles; Assistant Research Psychologist; Department of Psychiatry and Biobehavioral Science, UCLA, West Los Angeles VA Healthcare System, MIRECC, 11301 Wilshire Blvd., 210A, Los Angeles, CA, USA 90073, 310 478-3711 x 40770

\section{Michelle P. Salyers, PhD,}
Associate Professor of Psychology, Indiana University Purdue University Indianapolis, Department of Psychology, IUPUI School of Science (LD), 402 N Blackford Street, LD126B, Indianapolis, IN 46202-3275, 317.274.2904
Elizabeth W. Twamley, PhD, and Co-Chief, Neuropsychology Unit, Center of Excellence, VA San Diego Healthcare System; Associate Professor of Psychiatry, University of California, San Diego, Associate Professor of Psychiatry In Residence, University of California, San Diego, 140 Arbor Drive (0851), San Diego, CA 92103, (619) 497-6684

\footnotetext{
Alexander S. Young, MD 478-3711

Correspondence to: Matthew Chinman.

Conflict of Interest Statement: All the authors have no conflicts of interest to declare.
}

Director, Health Services Unit, VA Desert Pacific Mental Illness Research, Education and Clinical Center, Los Angeles; Professor of Psychiatry, UCLA, Los Angeles, West Los Angeles VA Healthcare System, MIRECC, 11301 Wilshire BIvd., 210A, Los Angeles, CA, USA 90073, 310 


\section{Abstract}

Use of Peer Specialists (PSs) - individuals with serious mental illness who use their experiences to help others with serious mental illness-is increasing. However, their impact on patient outcomes has not been demonstrated definitively. This cluster randomized, controlled trial within the Veterans Health Administration compared patients served by three intensive case management teams that each deployed two PSs for one year, to the patients of three similar teams without PSs (Usual Care). All patients (PS group=149, Usual Care=133) had substantial psychiatric inpatient histories and a primary Axis 1 psychiatric disorder. Before and after the year PSs worked, patients were surveyed on their recovery, quality of life, activation (health self-management efficacy), interpersonal relations, and symptoms. Patients in the PS group improved significantly more $(\mathrm{z}=2.00, \mathrm{df}=1, \mathrm{p}=0.05)$ than those receiving Usual Care on activation. There were no other significant differences. PSs helped patients become more active in treatment, which can promote recovery.

\section{INTRODUCTION}

As stated in the 2003 U.S. President's New Freedom Commission on Mental Health, Peer Specialists (PSs) are widely seen as important in recovery-oriented mental health care ${ }^{1}$. PSs are individuals with serious mental illness (SMI) who draw upon lived experiences to provide services to others with SMI in clinical settings ${ }^{2}$. Although research generally supports PSs' inclusion in clinical settings, implementation has been uneven and outcomes have not been demonstrated definitively. Despite this, the use of PSs is growing. Twenty-two states now have Medicaid reimbursement for PSs. The Veterans Health Administration (VHA) has hired about 250 Peer Specialists (PSs) across most of its medical centers and plans to hire 800 more over the next two years per an executive order by the Obama administration. However, impact within the VHA has not yet been evaluated. The current study is the first within VHA to evaluate PSs' impact on recovery outcomes for veterans with SMI.

The current emphasis on recovery in the VHA and the larger service system necessitate a broad range of outcomes when examining program impact beyond symptom stabilization and maintenance. An increasing number of studies are emphasizing the role of patient activation in SMI recovery ${ }^{3-6}$. Patient activation refers to the knowledge, skill, confidence, and attitudes for managing health and treatment ${ }^{7}$. Several studies in medical domains have found that individuals with higher activation are healthier, report a better quality of life, are more satisfied with treatment, and engage in more healthcare practices ${ }^{7-10}$. As recovery involves an active role for people with SMI in developing a life beyond the illness ${ }^{11}$, activation can be a central construct in assessing the recovery impact of a new service like incorporating PSs.

PSs are in a unique position to help, consistent with social modeling theory, which states that similar others might have the most influence on behavior change ${ }^{12}$. They offer systems knowledge and "street smarts," and teach successful coping strategies ${ }^{13}$ that can enhance the use of illness self-management strategies. Often PSs increase patients' involvement in treatment ${ }^{14}$ because they are able to empathize, access social services, appreciate clients' 
strengths, be tolerant, flexible, patient, and persistent, and be aware of and responsive to clients' desires and goals ${ }^{15-17}$, even among persons who are homeless and have cooccurring psychiatric and substance disorders ${ }^{18}$. As a result, PSs have been successful in improving patient satisfaction with traditional mental health services ${ }^{19}$. PSs have reestablished their own social networks, and can help patients do the same, often through mutual support activities. Finally, PSs actively model the possibility of recovery, addressing the loss of hope often evidenced by those with SMI.

In addition to direct work with patients, PSs can further impact the care process by moving services toward a recovery orientation in several ways ${ }^{20}$. They often serve as an unofficial liaison to the non-consumer staff, interpreting, and in some cases mediating, between other staff and patients. They can challenge unacknowledged stigma ${ }^{21}$ and emphasize community integration over a singular focus on symptom stabilization ${ }^{22,23}$. Thus, PSs aim to change how patients engage with the community (i.e., become less isolated) and with providers (i.e., becoming more active in his/her care).

Seventeen studies, all outside VHA, have tested the use of PSs in traditional clinical settings -five RCTs, eight quasi-experimental studies (comparison groups, not randomized), and four descriptive or correlational studies-typically comparing patients over time from different types of case management teams with or without PSs. Eleven (two RCTs, six quasiexperimental, and three correlational) showed some positive benefit to patients served by PSs compared to patients who were not, including less inpatient use ${ }^{24-28}$, better treatment engagement ${ }^{16,29,30}$; greater satisfaction with life ${ }^{16}$, greater quality of life ${ }^{25}$, greater hopefulness ${ }^{31}$, better social functioning ${ }^{25}$, improved self-reported recovery ${ }^{23,32}$, fewer days homeless $^{32}$, and fewer problems and needs ${ }^{16,29,32}$. The other six studies did not yield differential improvement in a variety of clinical outcomes over time ${ }^{33-38}$. One study, a quasi-experimental trial comparing patients from four Assertive Community Treatment teams with PSs to 16 teams without, did show that the presence of a PS was associated with an increase in psychiatric hospitalization days ${ }^{32}$.

As a group, these studies do not show a clear advantage for incorporating PSs. One reason could be that most studies have either focused on symptoms and hospitalizations, rather than on the full range of recovery domains. In addition, prior studies may have not addressed common implementation barriers of employing PSs such as ill-defined PS roles and non-PS resistance, which have been well documented within $\mathrm{VHA}^{2,39}$. To overcome these difficulties, we conducted a randomized trial -- PEER (PEers Enhancing Recovery) -- using organizational implementation strategies to incorporate PSs into traditional VHA case management teams and test the impact of PSs on a broad range of recovery outcomes. Six full-time PSs were randomly assigned to work for a year on three of six VHA Assertive Community Treatment teams, an evidence-based, intensive case management model ${ }^{40}$, while the other three teams delivered Usual Care. In VHA, these teams are called MHICM (Mental Health Intensive Case Management) and are expected to adhere to Assertive Community Treatment practice (e.g., low caseloads, majority of contact in community). In PEER, it was hypothesized that the involvement of PSs would lead to greater gains-at the individual patient level—in recovery, quality of life, patient activation, and to a lesser extent, symptoms. 


\section{METHODS}

\section{Study Sites and Assignment to Study Condition}

PEER was a cluster randomized controlled trial ${ }^{41}$ on MHICM teams in six medium to large cities in Southwestern US. Using a random sequence generator by the study PI, three MHICM teams were assigned to receive two PSs each. The PSs were then hired after site randomization, which was done (versus patient randomization) to minimize potential contamination. To receive MHICM services in VHA, veterans must have at least 30 psychiatric inpatient days or three psychiatric admissions in the past year and have a primary Axis 1 psychiatric disorder. MHICM teams provide intensive, flexible community support to reduce psychiatric symptoms, substance abuse, and inpatient hospitalization; improve community adjustment and quality of life; enhance satisfaction with services; and reduce treatment $\operatorname{costs}^{42}$. The randomization yielded two groups from which patients were recruited: teams A $(n=135), B(n=53)$, and $C(n=64)$ were randomly assigned receive PSs and teams $D(n=89), E(n=75), F(n=52)$ were assigned to Usual Care. It was not possible to blind either participating patients or data collectors to study condition because VHA required different informed consent forms in PS and Usual Care teams, and patients knew when their team had a PS or not.

\section{PS Intervention on the MHICM Teams}

PEER used an organizational change framework - the Simpson Transfer Model ${ }^{43}$ - to guide the implementation of PSs through four stages: Exposure (e.g., training in PSs), Adoption (deciding to hire PSs), Implementation (deploying PSs), and Practice (monitoring and refining PS services). Research staff collaborated with MHICM staff at each stage and assisted the MHICM teams to hire, train, and supervise the PSs with ongoing consultation (See ${ }^{39}$ for more details of PEER's implementation process using the Simpson Transfer Model).

Consistent with previous PS descriptions ${ }^{44,45}$, PSs developed strong relationships with veterans and conducted all types of case management duties including delivering medication, accompanying veterans to appointments, developing recovery plans, meeting with veterans individually, leading and co-leading groups, engaging veterans into services, and helping other MHICM staff, all while drawing upon their own lived experiences. They participated fully in all MHICM activities including team meetings, meetings between veterans and psychiatrists, team-organized events and outings, and charting in the medical record. The PSs "floated"— i.e., they did not have their own caseload—because the teams have case managers assigned administrative responsibility for each patient and that they wanted the PSs to work with multiple veterans more readily.

Training and supervision-Prior to the providing services, PSs attended a 30-hour training conducted by the Peer-to-Peer Resource Center of the Depression and Bipolar Support Alliance on recovery, basic counseling skills, and psychosocial rehabilitation. The training and certification examination is based on the Georgia model of Medicaidreimbursed peer specialists ${ }^{46}$. PSs also received a two-day training in Illness Management and Recovery $\left(\mathrm{IMR}^{47}\right.$ ) by staff from the ACT Center of Indiana. IMR is an evidence-based, 
manualized approach to helping consumers with SMI learn information and skills to better manage illness and achieve goals. Illness Management and Recovery has been used successfully by PSs on ACT teams previously ${ }^{23,28}$ and it was believed this could provide some structure for their work. Finally, MHICM staff provided training on MHICM rules such as emergency procedures and clinical charting. PSs were supervised weekly by both an "internal" supervisor (MHCIM staff) and an "external" supervisor (PEER principal investigator, a licensed clinical psychologist). Research staff also met monthly with each MHICM team leader and PS supervisor to troubleshoot any implementation issues.

Although all veterans in the PS group had access to the PSs, medical records showed that $43 \%$ of enrolled veterans had zero PS contacts, $11 \%$ had one contact, $10 \%$ had $2-4$ contacts, $18 \%$ had 5-12 contacts, and $18 \%$ had greater than 13 contacts. However, the number of contacts was underestimated because PSs sometimes recorded contacts in the medical record incorrectly or not at all. Therefore, the analyses focused on the intent to treat approachcomparing all veterans from both groups-which is nonetheless consistent with how PSs are typically used (i.e., float and provide a range of services to some and not others) and the hypothesis that PSs can impact the recovery-orientation of a whole team.

Further, the impact of PSs was evaluated over and above the outpatient services patients were receiving in MHICM and the VHA more broadly. According to VHA administrative data on Behavioral Health outpatient service contacts tracked through a central electronic medical record (includes psychiatric, social work, substance use, and rehabilitation services), patients in the PS and Usual Care groups were receiving similar numbers of contacts (per month) in the year prior to study enrollment $\left(\mathrm{M}_{\mathrm{PS}}=1.61, \mathrm{SD}=2.44\right.$ in the PS group vs. $\mathrm{M}_{\mathrm{UC}}=1.73, \mathrm{SD}=2.45$ in the Usual Care group, $\mathrm{p}=0.52$ ). As could be expected with a case management service like MHICM in which patients join the team in a more acute state and then generally improve over time, the number of contacts a year after study enrollment decreased similarly in both groups to $\mathrm{M}_{\mathrm{PS}}=1.54, \mathrm{SD}=2.67$ vs. $\mathrm{M}_{\mathrm{UC}}=1.26$, $\mathrm{SD}=2.00$ (within group test, $\mathrm{p}=0.03$, interaction, $\mathrm{p}=0.12$ ).

\section{Data Collection}

Procedures-Start dates for PSs varied during the project because of different rates of hiring PSs, and patient data collection extended between October 2006 and May of 2011. The inclusion criterion was simply being a current patient on one of the six teams. All 468 veterans ( $\mathrm{N}_{\mathrm{PS}}=252$ in the PS group, $\mathrm{N}_{\mathrm{UC}}=216$ in the Usual Care group) who were active patients at the time from the six MHICM teams were eligible. All participants gave written informed consent and scored $100 \%$ on a 10-item true/false quiz on the details of their consent ${ }^{48}$. Participants in the PS group also signed separate consent forms to potentially receive services from a PS. Trained interviewers administered the patient outcome measures at baseline by reading the questions aloud and recording the patient's responses. The oneyear follow-up assessment repeated the same measures used at baseline. The study was approved by each of the participating VHA medical centers' local IRBs. 
Demographic variables-These variables were gathered as part of the interview process and included age, gender, race, ethnicity, living situation, education level, and age at which the individual began taking psychiatric medication or was first hospitalized for psychiatric reasons.

Patient outcomes-Perceptions of the recovery orientation of the program were assessed with the Recovery Self-Assessment (RSA), a 36 item survey that assesses domains of recovery-orientated practice (e.g., focus on life goals, involvement of patients in their own care $)^{49}$. The RSA has high internal consistency and is thought to represent a more recoveryoriented or recovery-supportive environment ${ }^{50}$.

Two measures of self-reported recovery were included. The Mental Health Recovery Measure (MHRM) is a 30-item, 5-point behaviorally-anchored self-report measure based upon recovery experiences of persons with psychiatric disabilities ${ }^{51,52}$. The MHRM total score has good validity, correlating strongly with the Empowerment Scale ${ }^{53}$ and Community Living Skills Scales ${ }^{54}$, yet assessing unique aspects of recovery. The Illness Management and Recovery Scale $^{55}$ (IMR) has 15 items (rated on 5-point behaviorally anchored scales) that assess progress toward goals, knowledge about mental illness, involvement with significant others and self-help, time in structured roles, impairment in functioning, symptom distress and coping, relapse prevention and hospitalizations, use of medications, and alcohol and drug use. A total IMR score is made of the mean of the items and has demonstrated good internal consistency, stability (test-retest after two weeks), and convergent validity, correlating with the Recovery Assessment Scale ${ }^{56}$ and the Colorado Symptom Index 57 .

Subjective ratings of overall quality of life and the quality of social relationships, daily life, and family interactions was assessed using a combination of selected scales from the Quality of Life Instrument-Brief Version (QOLI ${ }^{58-60}$, which been used extensively with a wide range of populations including those who are homeless, have a dual diagnosis, and are ethnic minorities. Because of low internal consistencies of subscales in our sample, a factor analysis was conducted which indicated that a larger scale that included the items from the overall quality of life, social relationships, daily life, and family interactions scales would be more reliable.

The mental health version of the Patient Activation Measure ${ }^{4}$ (PAM) is a single 13-item scale designed to assess patient's knowledge, skill, and confidence in health selfmanagement. Respondents endorse items (e.g., "I know what each of my prescribed medications do") on a scale from 1 ("disagree strongly") to 4 ("agree strongly"). This version has similar psychometric properties as the original 13-item PAM and correlates with related constructs in other samples of people with $\mathrm{SMI}^{4,5}$. The BASIS-R is a brief yet comprehensive instrument assessing a range of psychiatric symptoms and problems. It is valid and reliable in both inpatient and outpatient settings in populations with $\mathrm{SMI}^{61}$. In addition to the total score, the BASIS-R scales that were used were Interpersonal Relationships (5 items), Depression (6 items), and Psychosis (6 items). All items have five response options ranging from 0 to 4 , with higher scores indicating more problems. The total 
BASIS-R assesses an overall level of impairment, while the individual subscales assess more targeted domains.

\section{Data Analyses}

First, demographic variables (e.g., age, gender, race, Hispanic) were compared between the PS and Usual Care groups with chi-squares for categorical data and analyses of variance for age. Second, baseline scores of all patient outcome measures were compared between the PS and Usual Care groups with regression models that corrected for nesting of subjects within sites nested within treatment. Third, comparisons between the PS and Usual Care groups were completed with a series of regressions testing the interaction of group (PS vs Usual Care) and time (baseline vs follow-up) for each of the nine patient outcome measures. Like at baseline, measures were analyzed with mixed effect hierarchical regressions which accounted for the nesting of site under treatment, subjects within sites, and subjects over time. Models included site, age, race, ethnicity and the BASIS-R Total score, which was used as a marker for severity of mental illness at both assessment points. Models of the BASIS-R Total score and its subscales did not include the BASIS-R Total score as a covariate. Finally, an additional set of analyses compared the time effect separately for the PS and Usual Care groups for each patient outcome measure. These analyses were also completed with mixed effect regressions that accounted for nesting of subjects within sites, demographics, and the BASIS-R total score (for the non-BASIS outcomes). Since one PS site started earlier, those patients were not included in the analyses of the RSA, PAM, and QOLI. Due to the 1:1 nature of the data collection, there was no missing data. Stata (v12, 2012 College Station, TX) was used for all analyses.

\section{RESULTS}

\section{Enrollment and response rates}

Of the 468 current patients, 62 were deemed ineligible because MHICM staff believed they were inappropriate (e.g., too ill at the time to consent, $N_{P S}=26, N_{U C}=16$ ) or died before enrollment $\left(\mathrm{N}_{\mathrm{PS}}=8, \mathrm{~N}_{\mathrm{UC}}=12\right)$. Of 406 eligible veterans $\left(\mathrm{N}_{\mathrm{PS}}=218, \mathrm{~N}_{\mathrm{UC}}=188\right), 72$ refused $\left(\mathrm{N}_{\mathrm{PS}}=40, \mathrm{~N}_{\mathrm{UC}}=32\right)$ and 49 either could not be located, did not speak English, or were in another study ( $\mathrm{N}_{\mathrm{PS}}=29, \mathrm{~N}_{\mathrm{UC}}=23$ ), leaving 282 enrolled veterans or $69 \%$ of the total patient census of the teams: 149 in the PS group (68\%) and 133 in the Usual Care group (71\%).

Follow-up assessment rates across the three PS teams ranged from 71-95\% (overall $81 \%$ ), resulting from deaths $(\mathrm{n}=10)$, moving $(\mathrm{n}=7)$, and loss to follow-up $(\mathrm{n}=10)$. The follow-up assessment rates across the three Usual Care teams ranged from $80-88 \%$ (overall $82 \%$ ), resulting from deaths $(n=3)$, moving $(n=4)$, and loss to follow-up $(n=10)$. The follow-up rates of the two groups were similar (chi-sq=1.52, $\mathrm{df}=1, \mathrm{p}=0.22$ ), leaving 122 in the PS group and 116 in the Usual Care group. Comparison of the demographic variables and available patient outcomes at baseline between participants that completed the follow-up interviews ( $\mathrm{n}=238)$ and those that did not $(\mathrm{n}=44)$ did not differ, with one exception. Females were more likely to complete the interviews at both times than were males $(100 \%$ vs. $83 \%$, $\mathrm{p}=0.02)$. 


\section{Sample characteristics}

As shown in Table 1, both groups were mostly male (90\% in the PS group, $86 \%$ in the Usual Care group) and older (average age of PS group $=54.6 \mathrm{SD}=9.19$, Usual Care group $=51.9$, $\mathrm{SD}=11.13)$. The majority of the participants were White, although the PS group had more African-Americans (27\%) than the Usual Care group (11\%). Both groups were similar in that about a third had a high school education or less (PS group $=34 \%$, Usual Care group=31\%) and most lived alone (PS group=84\%, Usual Care group=76\%). Most participants in both groups began psychiatric treatment in their late 20s, although the PS group received medications at a younger age on average $(\mathrm{M}=26.9, \mathrm{SD}=8.0)$ than participants in the Usual Care group $(\mathrm{M}=29.5, \mathrm{SD}=11.1)$. At baseline the PS group had significantly higher (better) MHRM scores (85 vs. 78, $\mathrm{p}=0.005$ ) and lower (better) BASIS-R Depression (26 vs 29, $\mathrm{p}=0.02$ ) and total BASIS Scores (1.28 vs. 1.55, $\mathrm{p}=0.09$ ) (see Table 2).

At baseline, both PS and Usual Care groups had worse Psychosis and Depression subscale ratings than a national sample of 2,656 psychiatric inpatients and 3,222 outpatients ${ }^{62}$. Both groups had Interpersonal Relationship ratings that were worse than the outpatient sample, but better than the inpatient sample. Baseline scores on the PAM indicate that both groups were in the lowest of four possible levels of activation, suggesting that they tend to be more passive recipients of treatment ${ }^{63}$.

Leading up to the start of the study, all teams were similarly adherent to Assertive Community Treatment fidelity as documented by the FY 2005 MHICM Monitoring data collected by the Northeast Program Evaluation Center ${ }^{42}$. For example, all teams had provider caseload sizes below the limit of 15 (ranged from 10 to 14) and met the minimum criteria of at least $60 \%$ of contact made in the community (ranged from 84-97\%). Also, all teams had moderate to high fidelity (ranged 3.8 to 4.1, out of a high of 5) as measured by the DACTS, the established scale to measure fidelity of this type of case management team ${ }^{64,65}$. The teams' DACTS data showed that they were similarly adherent during the study period.

\section{Patient outcomes}

As shown in Table 2, analyses of the scores indicated that patients in the PS group improved more on the PAM scale than those in the Usual Care group, although the absolute value still reflects a low level of activation. There were no significant differences between treatment groups on the other outcome measures. The additional analyses by individual group showed several significant differences over time. The Usual Care group improved over time on the IMR scale, BASIS-R Total score, the BASIS-R Interpersonal scale, the BASIS-R Depression scale, and the Quality of Life scale. The PS group improved over time on the BASIS-R Interpersonal scale.

At the individual scale level for baseline and follow-up measures, the intrapersonal dependency varied from $0-0.83$; with the median value equaling 0.59 for the PS group participants and 0.56 for the Usual Care participants. Across the two groups the lowest rhos occurred on the Interpersonal Relations subscale of the BASIS-R and the overall measure of Quality of Life. At the site level, the inter-person dependency varied from 0-0.04 with a median value of 0.017 with the highest level for the MHRM scale. 


\section{DISCUSSION}

As the first study of PSs in VHA, the PEER project sought to evaluate the use of PSs using a comprehensive organizational implementation strategy and a wide range of patient outcomes. One of the study's hypotheses about impacts on patient activation was supported, while the other hypotheses were not. While receiving the same level of outpatient treatment, individuals receiving treatment on teams with PSs for a year improved more on patient activation than those in the Usual Care group. Other measures of recovery, quality of life, and symptoms did not differentially change between the PS and Usual Care groups. Using a sample that was typical of a VHA population, this study adds to the literature examining PSs on Assertive Community Treatment teams, and the activation findings are consistent with previous studies that also showed PSs improved treatment participation ${ }^{29,30}$. These findings are also consistent with a national survey of PS duties, in which promoting active participation was among the most commonly provided type of support ${ }^{45}$.

The impact PSs can have on patient activation could improve how patients engage in their mental health and medical care. Even a one point improvement on the PAM (about what was found in this study) has been found to predict improved health care utilization ${ }^{66}$. Yet, activation still may be lower in those with SMI as those with SMI receive less appropriate medical care and have worse health outcomes ${ }^{67-69}$. Thus, in this study, although there was a small improvement in activation, the absolute value still places the PS-assigned patients at a low level, which could be why the other outcome measures also did not show improvement. Other studies of patient activation suggest that while those with SMI may be ready and capable to engage with their providers, providers and patients may need assistance ${ }^{5}$, which PSs could provide. However, this study suggests that more PS services may be needed than was provided to elevate low active patients to a higher level of activation.

Limitations of the study should be noted. First, the study was a cluster randomized trial as whole teams were assigned to the PS or Usual Care groups. The impact of the individual teams may have exerted influence on the findings, although the mixed effect hierarchical regressions helped address this issue. Second, the analyses presented were intent-to-treat analyses, but about half the veterans in the PS group did not receive any PS services. Thus, these analyses may be a conservative underestimate of the true impact of the PSs. Although attempts were made to track all PS contacts, a combination of factors (PS unfamiliarity with charting, the electronic medical record not having codes for PS services) made the tracking unreliable, underestimating the total number of PS contacts, precluding analyses by PS contacts. Third, the study involved a small number of PSs $(n=6)$. Although the findings are suggestive of impacts in the VHA, it still represents a small sample of the more than 250 PSs VHA-wide. Fourth, data collectors were not blind to condition, however, the survey instruments were all structured, mitigating somewhat this limitation. Fifth, having the PSs serve on MHICM teams may have also limited the impact that could have been detected over and above VHA's most intensive outpatient service. In addition, PSs' need to "fit in" may have led them to abandon their peer role, which would have reduced the differences between the two groups. However, some studies have shown that PSs on ACT outside of the VA have had an impact and may be an important component of helping ensure a recovery-oriented approach $^{23,70,71}$. Sixth, one of the teams had a much larger group of patients than the others, 
which may have impacted the results. Finally, it is possible that patients improved in domains unmeasured here, for example, Hope, which is a construct that has been associated with peer support in other studies ${ }^{31}$. Future studies that closely track the amount and nature of PS contacts, vary the settings in which they work, assess other constructs such as Hope, and involve larger samples of PSs could help address the limitations of the current study.

\section{Implications for Behavioral Health}

The hiring of PSs is rapidly increasing, especially in VHA. Clinical managers and policy makers often struggle with how to best utilize PSs. This study of PSs, the first in VHA, found significantly greater improvements on patient activation among patients who were served by intensive case management teams with PSs, although their overall level of activation remained low. This finding is consistent with other research on PSs. Although PSs can play a variety of roles, clinical managers who hire PSs may want to ensure that improving patient activation is included in their range of duties.

\section{References}

1. New Freedom Commission on Mental Health. Final Report. Rockville, MD: DHHS; 2003. Achieving the Promise: Transforming Mental Health Care in America.

2. Chinman M, Lucksted A, Gresen R, et al. Early experiences of employing consumer-providers in the VA. Psychiatric Services. Nov; 2008 59(11):1315-1321. [PubMed: 18971408]

3. Druss BG, Zhao L, von Esenwein SA, et al. The health and recovery peer (HARP) program: A peerled intervention to improve medical self-management for persons with serious mental illness. Schizophr Res. 2010; 118:264-270. [PubMed: 20185272]

4. Green CA, Perrin NA, Polen MR, Leo MC, Hibbard JH, Tusler M. Development of the Patient Activation Measure for mental health. Administration and Policy in Mental Health and Mental Health. Jul; 2010 37(4):327-333.

5. Salyers MP, Matthias MS, Spann CL, Lydick JM, Rollins AL, Frankel RM. The role of patient activation in psychiatric visits. Psychiatric Services. 2009; 60:1535-1539. [PubMed: 19880475]

6. Salyers MP, Matthias MS, Sidenbender S, Green A. Patient Activation in Schizophrenia: Insights from Stories of Illness and Recovery. Administration and policy in mental health and mental health services research. Aug 31.2012

7. Hibbard JH, Stockard J, Mahoney ER, Tusler M. Development of the Patient Activation Measure (PAM): Conceptualizing and measuring activation in patients and consumers. Health Services Research. Aug; 2004 39(4 Pt 1):1005-1026. [PubMed: 15230939]

8. Hibbard JH, Mahoney ER, Stockard J, Tusler M. Development and testing of a short form of the patient activation measure. Health Services Research. Dec; 2005 40(6 Pt 1):1918-1930. [PubMed: 16336556]

9. Hibbard JH, Mahoney ER, Stock R, Tusler M. Do increases in patient activation result in improved self-management behaviors? Health Services Research. Aug; 2007 42(4):1443-1463. [PubMed: 17610432]

10. Greene J, Hibbard JH. Why does patient activation matter? An examination of the relationships between patient activation and health-related outcomes. J Gen Intern Med. May; 2012 27(5):520 526. [PubMed: 22127797]

11. Anthony WA. Recovery from mental illness: The guiding vision of the mental health service system in the 1990s. Psychosocial Rehabilitation Journal. 1993; 16:11-23.

12. Bandura, A. Social Learning Theory. New York: General Learning Press; 1977.

13. Carlson LS, Rapp CA, McDiarmid D. Hiring consumer-providers: Barriers and alternative solutions. Community Mental Health Journal. Jun; 2001 37(3):199-213. [PubMed: 11440422] 
14. Chinman MJ, Allende M, Weingarten R, Steiner J, Tworkowski S, Davidson L. On the road to collaborative treatment planning: Consumer and provider perspectives. Journal of Behavioral Health Services \& Research. May; 1999 26(2):211-218. [PubMed: 10230148]

15. Davidson, L., Weingarten, R., Steiner, J., Stayner, D., Hoge, MA. Integrating prosumers into clinical settings. In: Mowbray, D.Moxley, C.Jasper, C., Howell, LL., editors. Consumers as Providers in Psychiatric Rehabilitation. Columbia, MD: International Association of Psychosocial Rehabilitation Services; 1997. p. 437-455.

16. Felton CJ, Stastny P, Shern DL, et al. Consumers as peer specialists on intensive case management teams: Impact on client outcomes. Psychiatric Services. Oct; 1995 46(10):1037-1044. [PubMed: 8829785]

17. Mowbray, CT., Moxley, DP. Consumers as providers: Themes and success. In: Mowbray, CT.Moxley, DP.Jasper, CA., Howell, LL., editors. Consumers as Providers in Psychiatric Rehabilitation. Columbia, MD: International Association of Psychosocial Rehabilitation Services; 1997.

18. Fisk D, Rowe M, Brooks R, Gildersleeve D. Integrating consumer staff into a homeless outreach project: Critical issues and strategies. Psychiatric Rehabilitation Journal. 2000; 23:244-252.

19. Hodges JQ, Markward M, Keele C, Evans CJ. Use of self-help services and consumer satisfaction with professional mental health services. Psychiatric Services. Aug; 2003 54(8):1161-1163. [PubMed: 12883147]

20. Bevilacqua, JL., Gettys, D., Cousins, V. Mental health systems development: Benefits created by consumer engagement. In: Mowbray, CT.Moxley, DP.Jasper, CA., Howell, LL., editors. Consumers as Providers in Psychiatric Rehabilitation. Columbia, MD: International Association of Psychosocial Rehabilitation Services; 1997.

21. Dixon L, Krauss N, Lehman A. Consumers as service providers: The promise and challenge. Community Mental Health Journal. Dec; 1994 30(6):615-625. [PubMed: 7835046]

22. Davidson L, Stayner DA, Nickou C, Styron TH, Rowe M, Chinman ML. "Simply to be let in": Inclusion as a basis for recovery. Psychiatric Rehabilitation Journal. Spring;2001 24(4):375-388. [PubMed: 11406988]

23. Salyers MP, Hicks LJ, McQuire AB, Baumgardner H, Ring K, Kim H. A pilot to enhance the recovery orientation of assertive community treatment through peer-provided illness management and recovery. American Journal of Psychiatric Rehabilitation. 2009; 12(3):191-204.

24. Clarke GN, Herinckx HA, Kinney RF, et al. Psychiatric hospitalizations, arrests, emergency room visits, and homelessness of clients with serious and persistent mental illness: findings from a randomized trial of two ACT programs vs. usual care. Ment Health Serv Res. Sep; 2000 2(3):155164. [PubMed: 11256724]

25. Klein AR, Cnaan RA, Whitecraft J. Significance of peer social support with dually diagnosed clients: Findings from a pilot study. Research on Social Work Practice. Sep; 1998 8(5):529-551.

26. Landers GM, Zhou M. An analysis of relationships among peer support, psychiatric hospitalization, and crisis stabilization. Community Mental Health Journal. Feb; 2011 47(1):106112. [PubMed: 19551502]

27. Min S-Y, Whitecraft J, Rothbard AB, Salzer MS. Peer support for persons with co-occurring disorders and community tenure: A survival analysis. Psychiatric Rehabilitation Journal. Win;2007 30(3):207-213. [PubMed: 17269271]

28. Salyers MP, McGuire AB, Rollins AL, Bond GR, Mueser KT, Macy VR. Integrating assertive community treatment and illness management and recovery for consumers with severe mental illness. Community Mental Health Journal. Aug; 2010 46(4):319-329. [PubMed: 20077006]

29. Craig T, Doherty I, Jamieson-Craig R, Boocock A, Attafua G. The consumer-employee as a member of a Mental Health Assertive Outreach Team. I. Clinical and social outcomes. Journal of Mental Health. Feb; 2004 13(1):59-69.

30. Sells D, Davidson L, Jewell C, Falzer P, Rowe M. The treatment relationship in peer-based and regular case management for clients with severe mental illness. Psychiatric Services. Aug; 2006 57(8):1179-1184. [PubMed: 16870970]

31. Cook JA, Copeland ME, Corey L, et al. Developing the evidence base for peer-led services: Changes among participants following Wellness Recovery Action Planning (WRAP) education in 
two statewide initiatives. Psychiatric Rehabilitation Journal. Autumn;2010 34(2):113-120. [PubMed: 20952364]

32. van Vugt MD, Kroon H, Delespaul P, Mulder CL. Consumer-Providers in Assertive Community Treatment Programs: Associations With Client Outcomes. Psychiatric Services. 2012; 63:477-481. [PubMed: 22388475]

33. Chinman MJ, Rosenheck R, Lam JA, Davidson L. Comparing consumer and nonconsumer provided case management services for homeless persons with serious mental illness. J Nerv Ment Dis. Jul; 2000 188(7):446-453. [PubMed: 10919704]

34. Chinman MJ, Weingarten R, Stayner D, Davidson L. Chronicity reconsidered: improving personenvironment fit through a consumer-run service. Community Mental Health Journal. Jun; 2001 37(3):215-229. [PubMed: 11440423]

35. O’Donnell M, Parker G, Proberts M, et al. A study of client-focused case management and consumer advocacy: The Community and Consumer Service Project. Australian and New Zealand Journal of Psychiatry. Oct; 1999 33(5):684-693. [PubMed: 10544992]

36. Rivera JJ, Sullivan AM, Valenti SS. Adding consumer-providers to intensive case management: Does it improve outcome? Psychiatric Services. Jun; 2007 58(6):802-809. [PubMed: 17535940]

37. Schmidt LT, Gill KJ, Pratt CW, Solomon P. Comparison of service outcomes of case management teams with and without a consumer provider. American Journal of Psychiatric Rehabilitation. 2008; 11:310-329.

38. Solomon P, Draine J. The efficacy of a consumer case management team: 2-year outcomes of a randomized trial. J Ment Health Adm. Spring;1995 22(2):135-146. [PubMed: 10142127]

39. Chinman M, Shoai R, Cohen A. Using organizational change strategies to guide peer support technician implementation in the Veterans Administration. Psychiatric Rehabilitation Journal. 2010; 33(4):269-277. [PubMed: 20374985]

40. Stein LI, Test MA. Alternative to mental hospital treatment. I. Conceptual model, treatment program, and clinical evaluation. Archives of General Psychiatry. Apr; 1980 37(4):392-397. [PubMed: 7362425]

41. Donner A, Klar N. Pitfalls of and controversies in cluster randomization trials. American Journal of Public Health. Mar; 2004 94(3):416-422. [PubMed: 14998805]

42. Neale, M., Rosenheck, R., Castrodonatti, J., Martin, A., Morrissey, J., Michele D’Amico, M. MHICM in the Department of Veterans Affairs: The Ninth National Performance Monitoring Report - FY 2005. West Haven, CT: VA Northeast Program Evaluation Center; 2006.

43. Simpson DD. A conceptual framework for transferring research to practice. Journal of Substance Abuse Treatment. Jun; 2002 22(4):171-182. [PubMed: 12072162]

44. Chinman M, Young AS, Hassell J, Davidson L. Toward the implementation of mental health consumer provider services. The Journal of Behavioral Health Services and Research. Apr; 2006 33(2):176-195. [PubMed: 16645906]

45. Salzer MS, Schwenk E, Brusilovskiy E. Certified peer specialist roles and activities: Results from a national survey. Psychiatric Services. 2010; 61:520-523. [PubMed: 20439376]

46. Sabin JE, Daniels N. Managed care: Strengthening the consumer voice in managed care: VII. The Georgia peer specialist program. Psychiatric Services. Apr; 2003 54(4):497-498. [PubMed: 12663836]

47. Hasson-Ohayon I, Roe D, Kravetz S. A randomized controlled trial of the effectiveness of the illness management and recovery program. Psychiatric Services. Nov; 2007 58(11):1461-1466. [PubMed: 17978257]

48. Stiles PG, Poythress NG, Hall A, Falkenbach D, Williams R. Improving understanding of research consent disclosures among persons with mental illness. Psychiatric Services. Jun; 2001 52(6):780785. [PubMed: 11376225]

49. O’Connell M, Tondora J, Croog G, Evans A, Davidson L. From rhetoric to routine: Assessing perceptions of recovery-oriented practices in a state mental health and addiction system. Psychiatric Rehabilitation Journal. Spring;2005 28(4):378-386. [PubMed: 15895922]

50. Campbell-Orde, T., Chamberlin, J., Carpenter, J., Leff, HS. Measuring the Promise: A Compendium of Recovery Measures, Volume II. Cambridge, MA: Human Services Research Institute; 2005. 
51. Young SL, Ensing DS. Exploring recovery from the perspective of people with psychiatric disabilities. Psychiatric Rehabilitation Journal. 1999; 22:219-231.

52. Bullock, WA., Young, SL. The Mental Health Recovery Measure (MHRM). Paper presented at: 111th annual meeting of the American Psychological Association Meeting; August, 2003; Toronto, Canada.

53. Rogers E, Chamberlin J, Ellison ML, Crean T. A consumer-constructed scale to measure empowerment among users of mental health services. Psychiatric Services. Aug; 1997 48(8): 1042-1047. [PubMed: 9255837]

54. Smith MK, Ford J. Measuring the emotional/social aspects of loneliness and isolation. Journal of Social Behavior and Personality. 1990; 2:257-270.

55. Mueser, KT., Gingerich, S., Salyers, MP., McGuire, AB., Reyes, RU., Cunningham, H. The Illness Management and Recovery (IMR) Scale. Concord, NH: New Hampshire-Dartmouth Psychiatric Research; 2004.

56. Corrigan PW, Salzer M, Ralph RO, Sangster Y, Keck L. Examining the factor structure of the recovery assessment scale. Schizophrenia Bulletin. 2004; 30(4):1035-1041. [PubMed: 15957202]

57. Conrad KJ, Yagelka JR, Matters MD, Rich AR, Williams V, Buchanan M. Reliability and validity of a modified Colorado Symptom Index in a national homeless sample. Ment Health Serv Res. Sep; 2001 3(3):141-153. [PubMed: 11718206]

58. Lehman, A., Kernan, E., Postrado, L. Toolkit for evaluators: quality of life for persons with severe mental illness. Baltimore, MD: Center for Mental Health Services Research. University of Maryland School of Medicine, Department of Psychiatry; 1988.

59. Lehman AF. The well-being of chronic mental patients. Archives of General Psychiatry. Apr; 1983 40(4):369-373. [PubMed: 6838316]

60. Lehman AF. A quality of life interview for the chronically mentally ill. Evaluation and Program Planning. 1988; 11:51-52.

61. Eisen SV, Normand SL, Belanger AJ, Spiro A 3rd, Esch D. The Revised Behavior and Symptom Identification Scale (BASIS-R): Reliability and validity. Med Care. Dec; 2004 42(12):1230-1241. [PubMed: 15550803]

62. Eisen, S., Normand, S., Belanger, A. BASIS-32® and the Revised Behavior and Symptom Identification Scale (BASIS-R). In: Maruish, M., editor. The Use of Psychological Testing for Treatment Planning and Outcome Assessment. 3. Vol. 3. Mahwah, NJ: Lawrence Erlbaum Associates; 2004. p. 79-115.

63. Hibbard, JH., Cunningham, P. How engaged are consumers in their health and health care, and why does it matter. Health System Change Issue Brief, 8. Washington, DC: Center for Studying Health System Change; 2008.

64. McGrew JH, Bond GR, Dietzen L, Salyers M. Measuring the fidelity of implementation of a mental health program model. J Consult Clin Psychol. Aug; 1994 62(4):670-678. [PubMed: 7962870]

65. Teague GB, Bond GR, Drake RE. Program fidelity in assertive community treatment: Development and use of a measure. Am J Orthopsychiatry. Apr; 1998 68(2):216-232. [PubMed: 9589760]

66. Remmers, CLG. The relationship between the patient activation measure, future health outcomes, and health care utilization among patients with diabetes. Public Health, Walden University; 2008.

67. Druss BG, Bradford DW, Rosenheck RA, Radford MJ, Krumholz HM. Mental disorders and use of cardiovascular procedures after myocardial infarction. JAMA. Jan 26; 2000 283(4):506-511. [PubMed: 10659877]

68. Druss BG, Bradford WD, Rosenheck RA, Radford MJ, Krumholz HM. Quality of medical care and excess mortality in older patients with mental disorders. Archives of General Psychiatry. Jun; 2001 58(6):565-572. [PubMed: 11386985]

69. Goldberg RW, Kreyenbuhl JA, Medoff DR, et al. Quality of diabetes care among adults with serious mental illness. Psychiatric Services. Apr; 2007 58(4):536-543. [PubMed: 17412857]

70. Salyers MP, Rollins AL, Clendenning D, McGuire AB, Kim E. Impact of illness management and recovery programs on hospital and emergency room use by medicaid enrollees. Psychiatric Services. 2011; 62(5):509-515. [PubMed: 21532077] 
71. Salyers M, Stull L, Rollins A, Hopper K. The work of recovery on two assertive community treatment teams. Administration and Policy in Mental Health and Mental Health Services Research. 2011; 38(3):169. [PubMed: 20839045] 


\section{Table 1}

Description of the study subjects at Baseline ${ }^{1}$

\begin{tabular}{|c|c|c|c|}
\hline \multirow[t]{2}{*}{ Demographic variables } & PS $(n=122)$ & Usual Care $(n=116)$ & PS vs Usual Care \\
\hline & $\mathbf{N}(\%)$ & $\mathbf{N}(\%)$ & $X^{2}(\mathbf{d f}), p$ \\
\hline \multicolumn{4}{|l|}{ Race } \\
\hline African-American non-Hispanic & $32(26 \%)$ & $12(10 \%)$ & $9.71(4), 0.046^{2}$ \\
\hline White non-Hispanic & $61(50 \%)$ & $68(59 \%)$ & \\
\hline Biracial non-Hispanic & $8(7 \%)$ & $10(9 \%)$ & \\
\hline African-American Hispanic & $1(1 \%)$ & $1(1 \%)$ & \\
\hline White Hispanic & $15(12 \%)$ & $19(16 \%)$ & \\
\hline No Race/ethnicity information & $5(4 \%)$ & $6(5 \%)$ & \\
\hline Hispanic & $16(13 \%)$ & $20(17 \%)$ & $0.79(1), .374$ \\
\hline Male & $110(90 \%)$ & $100(87 \%)$ & $0.60(1), .437$ \\
\hline \multicolumn{4}{|l|}{ Education } \\
\hline$<=\mathrm{HS}$ & $42(36 \%)$ & $36(34 \%)$ & $0.91(2), .634$ \\
\hline Some post high school training & $61(57 \%)$ & $60(52 \%)$ & \\
\hline College degree or more & $14(9 \%)$ & $9(9 \%)$ & \\
\hline \multicolumn{4}{|l|}{ Current Marital Status } \\
\hline Never Married & $49(42 \%)$ & $39(37 \%)$ & $0.97(2), .616$ \\
\hline Currently Married (includes those with previous divorces \& current partners) & $24(21 \%)$ & $27(26 \%)$ & \\
\hline Divorced or separated & $44(38 \%)$ & $39(37 \%)$ & \\
\hline \multirow[t]{2}{*}{ Lives Alone } & $102(87 \%)$ & $88(84 \%)$ & $0.51(1), .475$ \\
\hline & Mean (sd) & Mean (sd) & t-test (df), p \\
\hline Age & $54.59(9.19)$ & $51.89(11.13)$ & $2.05(236), p=.042$ \\
\hline Age first meds & $26.89(8.04)$ & $29.49(10.28)$ & 2.09 (215), $\mathrm{p}=.004$ \\
\hline Age first hospitalization & $27.00(8.65)$ & $30.20(10.76)$ & $2.40(211), \mathrm{p}=.017$ \\
\hline
\end{tabular}

${ }^{1}$ Since only 4 people reported being employed ( 2 in each condition), it was too few to include in the table.

2 This significant difference is due to the over representation of African-American subjects in the PS group. With African-American subjects excluded, $X^{2}(d f), p=0.44(3), p=0.98$. 


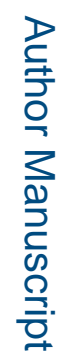

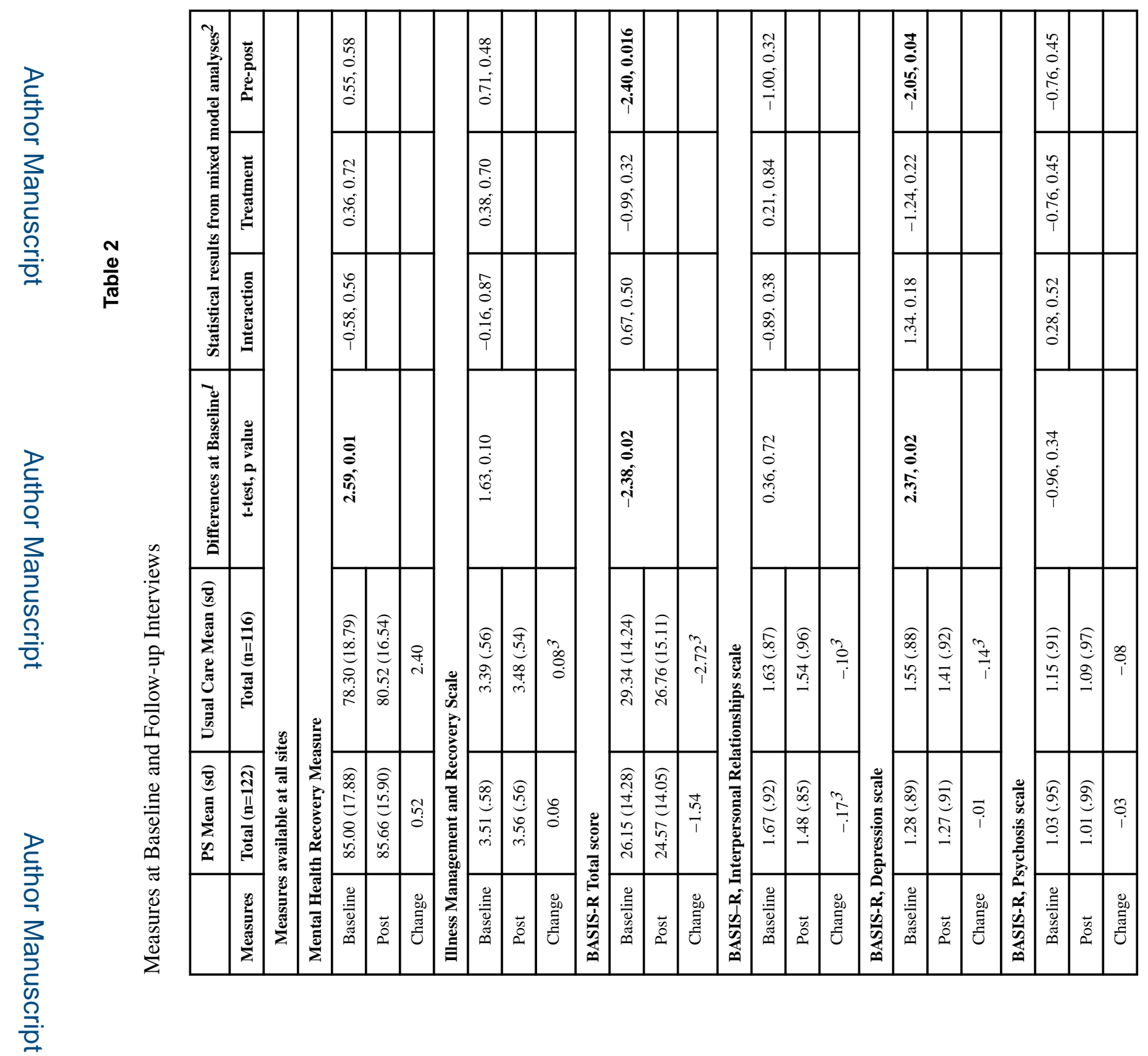

J Behav Health Serv Res. Author manuscript; available in PMC 2017 October 20. 


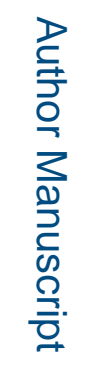

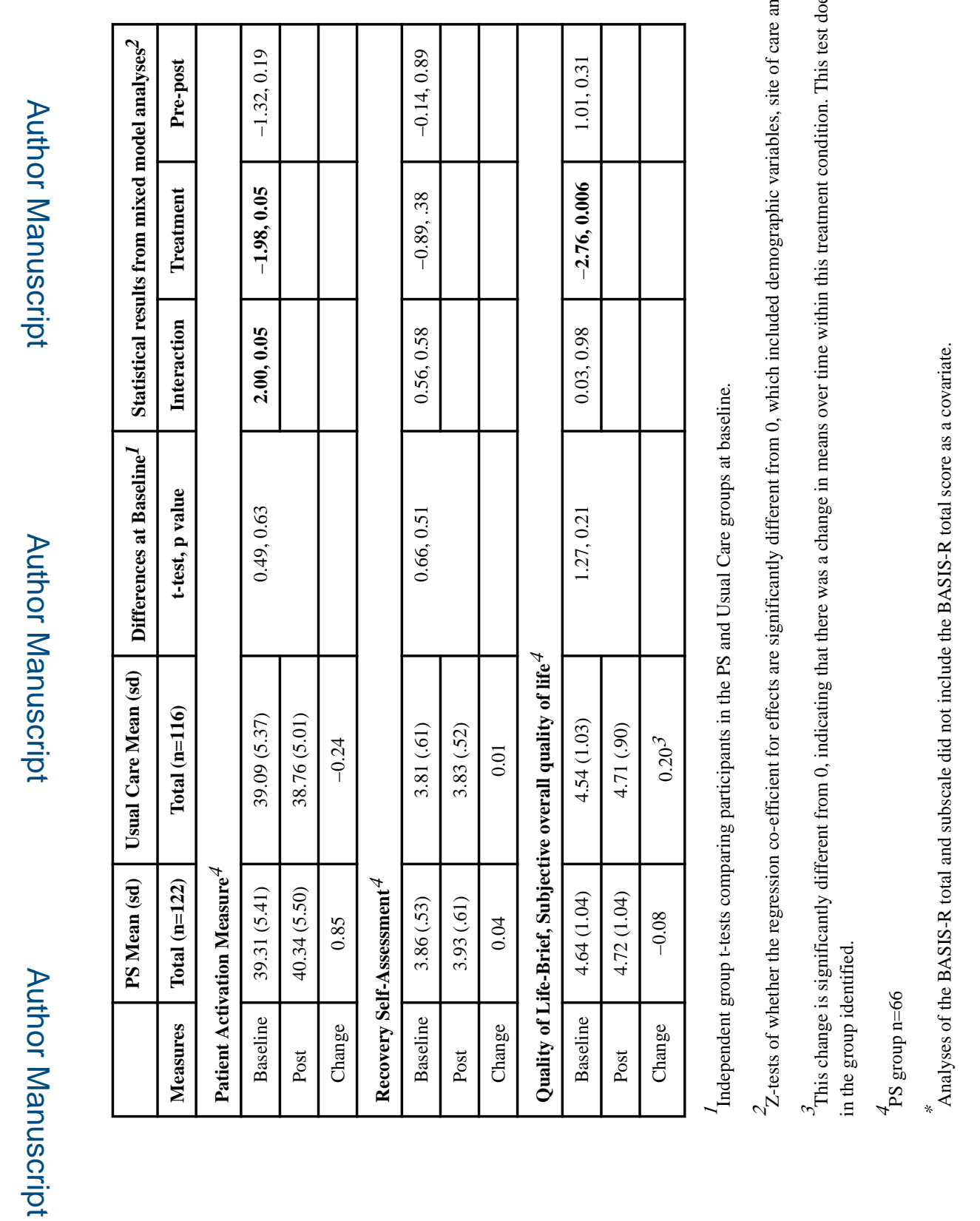

J Behav Health Serv Res. Author manuscript; available in PMC 2017 October 20. 